\title{
Some Impressions of Physiotherapy Practice in Europe
}

\author{
By A. C. PETRICK, Dip. Phys. Pretoria, R.N. Pretoria.
}

When I left South Africa for Europe in November 1962, I had planned not only to travel and incidentally to visit clinics, but also to work at various centres so as to gain experience in overseas physiotherapy practice.

I found, however, that few institutions were willing to employ a visiting physiotherapist for short periods of, say one or two months. Although I was disappointed at first, I shall never regret my final decision to work for six months at Bad Ragaz in Switzerland.

Bad Ragaz, situated (as shown in a rough sketch below) at the eastern border of Switzerland, is a well-known Swiss spa-clinic.

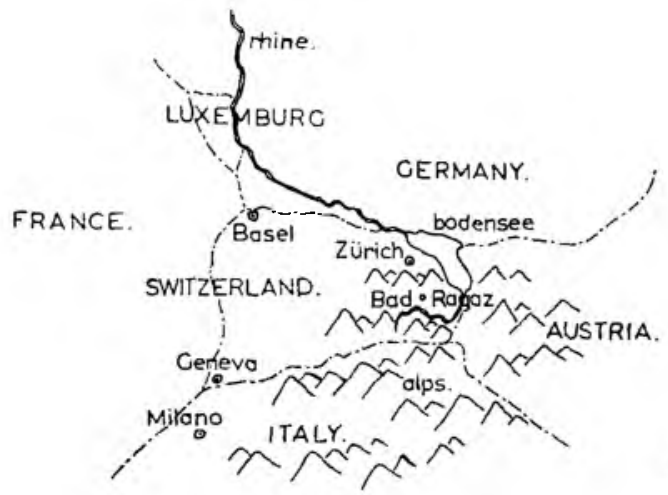

FIC. 1.

In a deep long gorge in the mountain there is a thermal spring. Its water is taken down to the clinic in well insulated pipes. The water is highly mineralised, and has a temperature of $37^{\circ} \mathrm{C}\left(95^{\circ} \mathrm{F}\right)$ at the source and about $33^{\circ} \mathrm{C}\left(90^{\circ} \mathrm{F}\right)$ in the thermal pools and in the therapy pool. The European (speaking of inhabitants of the Continent and the British Isles) has as much faith in the healing power of this thermal water, as the Israelites of the Bible had in the Bethesda-pool. In fact you can distinguish a true European from an alien by just this fact. The Bad Ragaz water is, however, famous beyond the borders of Europe, as Americans (from the South and North), Indians, Africans, Israelites and even a few South Africans came to visit the spa. Ragaz is the Italian word for "young" and these people evidently believed that Bad Ragaz made you young. No wonder the motto is: "In Bad Ragaz pfeift jeder Spatz Du wirst gesund und Jung in Bad Ragaz". (In Bad Ragaz each sparrow chirps you become well and young here).

Most of the visitors first consulted the doctor, especially if there was any possibility of circulatory trouble, to determine whether the daily warm bath would have any ill effect on them. They started off very carefully with these baths; 5-10 minutes the first day, gradually increasing the time by $1-2$ minutes each day till the maximum of 20 minutes was reached. The European, unused to such hot baths, becomes too fatigued by the water.

These Kur (or healing) guests were then classified into various groups. There were those taking their own baths in the single pools or in the big pools and receiving full massages which invigorates them so much that they feel younger than ever. They would then complete their "healing holiday" with trips to the surrounding countryside, mountaineering fishing, riding and playing golf; ending off with dancing and dining in the exquisite hotel clubs.

Then there were the others who really needed treatment -skiing injuries, accident injuries, circulatory and respiratory conditions, rheumatics and various kinds of palsies.

Most guests paid for their own treatments (the cost ranging from $R 1.40--R 2.20$ per treatment, depending on the type and duration of the treatment).

All accident cases falling under the control of the Swiss Invalid Fund Scheme-whether they want to or not have to go on a three weeks Kur (or healing holiday) to some approved clinic each year or else join a sports group at some place.

At the clinic there were patients of all ages and in all kinds of conditions together, doing swimming, gymnastics and games. As far as possible hemiplegics, paraplegics and cerebral palsies were kept together; children together and so on, but it was a difficult task, and often large general groups had to be handled as best as could be arranged under the circumstances. They enjoyed these sessions tremendously as it gave them an extra boost.

In Switzerland most invalids who are at all able to handle a vehicle, have their own hand controlled cars, supplied to them by the Invalid Fund.

Dr. Zinn, the chief medical officer at Bad Ragaz is a rheumatologist and a very good diagnostician. He is assisted by an internal specialist, two orthopaedic surgeons and eight physiotherapists. The latter, all girls, came from Britain, Germany, Switzerland, Australia and South Africa The radiotherapy and occupational therapy centre is excellent. Unfortunately there were no speech therapists. The clinic is also visited weekly by a gynaecologist, psychologist, neurologist and an orthopaedic surgeon.

Dr. Zinn arranged for one hour meetings on Tuesday and Friday afternoons when we could pose our problems and discuss them. We were also encouraged to consult any of the doctors about any special problem as it arose. The cooperation among the staff was a wonderful experience.

Each Tuesday evening we had a lecture, either given by Dr. Zinn or some guest speaker who had been or was doing pioneering work in some specific field. In this way we had lectures on mouth-to-mouth artificial respiration and external cardiac massage from a first aid unit; water therapy as done in Germany; cerebral palsy as done in Switzerland and post operative cancer work as done in Canada (especially decreasing the oedemas often following big operations like a mastectomy) and about District Physiotherapy as done in Britain. We also had the honour to work with Miss Dena Gardiner from July to September, getting valuable knowledge from her very interesting lectures-especially on P.N.F. in specific conditions.

The reader may gather from this brief summary, that such lectures and the co-operative activity at Bad Ragaz were very stimulating.

It is impossible to go into details in such a general article, but a few notes on some of the ideas and techniques I came across and some of the impressions gained during my stay there may be of interest. 
First I would draw attention to:

District Physiotherapy:

Would it not be a wonderful thing if one could start a Whysiotherapy unit in out-lying district of each province? It is of such great value and would enable one proving much, for example:

1. Possibility for treatment and checking of cases who, ither through pecuniary or working considerations cannot so easily go to hospitals or clinics in the larger wns. One can appreciate this in South Africa, where big centres are often so very far away from the farms and small towns. This would also make things easier for those patients for whom the to and fro travelling is too exhausting. (I am especially thinking of older people here).

2. Treatment and checking of post operative cases, 2. Trearlier discharges from hospital possible.

3. Earlier diagnosis and treatment of e.g. C.H.D. Perthes' disease, slight C.P. and such cases.

4. School and home problems of children and patients could be seen and coped with.

5. Checking apparatus (that it is correctly used and still fits properly) especially in the case of children and amputees.

6. The district physiotherapist could also help the chronic pulmonary cases with their breathing exercises and postural drainage.

The physiotherapist should be able to drive to different homes and farms-by car-if necessary, having with her P.O.P., case notes, bandages and whatever may be necessary. It is, however, desirable to have patients come to a central clinic somewhere, if at all possible. The physiotherapist should naturally co-operate closely with the public health officers, district nurses, and, if available, occupational and speech therapists.

\section{Splints and Artificial Limbs.}

I would mention that in Bad Ragaz we made all our P.O.P.-splints ourselves.

We were also taught to make light polythene arm splints and felt neck cuffs.

While at Heidelberg I noticed the splint developed in the Heidelberg orthopaedic clinic. These splints have a metal footpiece, covered with leather. For full length, or full support below-knee calipers, this footpiece has leather sides which tie with laces on top of the foot. On to this the supporting metal pieces required are attached. Both these have the advantage that in the case of children they can, very simply, be lengthened according to the child's growth. The below knee ant. tibial support also has the foot piece, with just an iron at the back fastened below the knee with a leather strap.

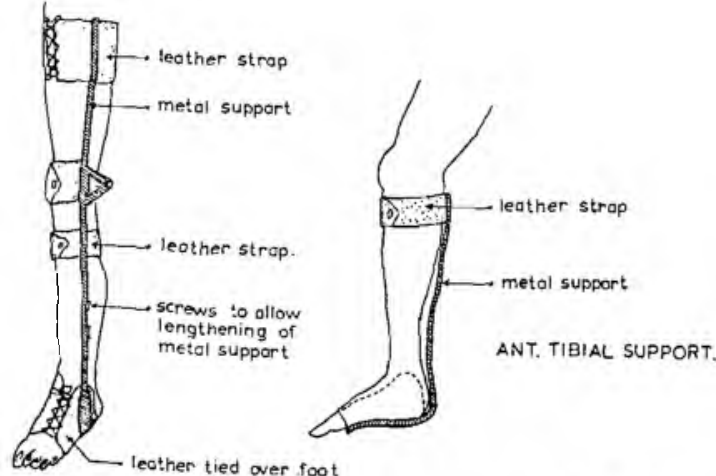

FULL LENGTH OR BELOW KNEE CALIPER

FIG 2
The advantage is, that these people are now able to wear different shoes with these splints. High lace-ups do not necessarily have to be worn. The immense value-both cosmetic and psychological, to both men and women can easily be appreciated. Children also do not need new calipers each time-a fact that helps, especially the poorer patient tremendously. One uses the fore-foot push-off-action (making the movements more natural) because the footpiece is moulded up to the anterior arch.

The wooden vacuum attached artificial leg obtainable in Germany should also be of great interest to us. It is built to contour and with a good knee joint. Only one slight thin belt is tied around the wajst, no other straps are necessary. Air is sucked out of the vacuum and it clings as if it were a real limb. It is released by letting air into the vacuum. It is very light and very much appreciated by the patients.

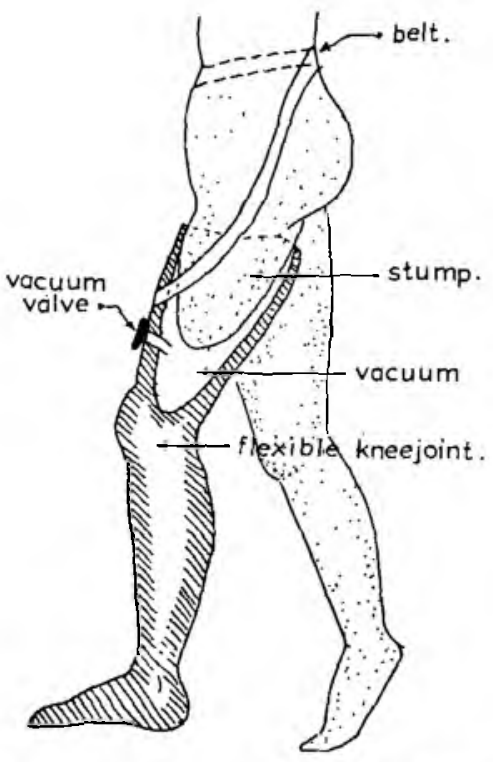

ARTIFICIAL WOODEN VACUUM LEG

FIG. 3 .

\section{Testing and Records:}

At Bad Ragaz all patients with any joint condition had to have a full "joint test" on admission, comprising, e.g.:

(i) Range of movement: left and right;

(ii) Circumferences (joints and/or limbs);

(iii) Power-with long levers, joints at right angles-determination of the maximum weight the patient could hold for three seconds (use sandbags or weights);

(iv) Functional ability.

Charts, similar to muscle testing charts, were made up for the upper and lower extremities and for the trunk.

\section{Power of the handgrip:}

Tested with a dynamometer. A simple pressure meter, with a rubber bulb attached which had to be pressed. The reading was in pounds/square inch. 


\section{Internal Rotation of the Shoulder:}

The patient is told to reach as high as possible behind the back first with the right and then with the left hand. Measure the distance from the thumb-tip to the tip of the seventh cervical vertebra. When comparing the two distances it should be remembered that the "writing hand" will never go as high as the "non-writing hand." (due to the greater tone in the muscles of the most used joint).

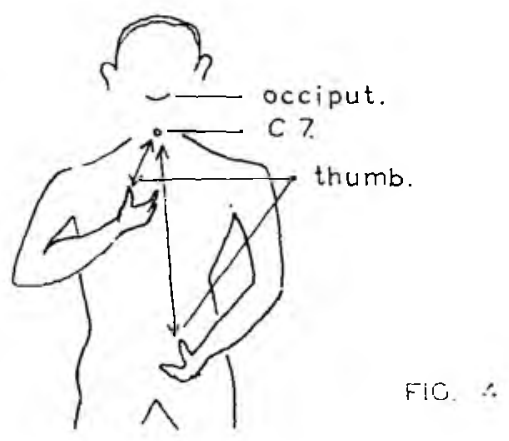

\section{In- and eversion of the Foot:}

Measure from the medial malleolus to the first metatarsal head in dorsiffexion, in midposition. Invert and measure again. The difference indicates the amount of inversion. Repeat for eversion, measuring from the lateral malleolus to the fifth metatarsal head.

\section{Functional Tests:}

Arms: Can they touch their head (combing hair), necks (fastening buttons), tie an apron, wring out a towel and support?

Legs: How is their gait, can they go up steps, do they need an aid?

In all chest cases measurements were also made at the commencement of treatment, and thereafter once every week to determine progress in chest expansion.

Measurements were made at :

(i) axilla level,

(ii) nipple line level,

(iii) diaphragm level.

\section{TREATMENT AND EXERCISES.}

(a) It is of interest to note the position used for patients with acute backaches (disc lesions, strains, etc.). The patient lies on a firm mattress and fracture board as is usual. Two firm but soft leather cushions, high enough to allow about $90^{\circ}$ flexion at both hips and knees are put under the legs.

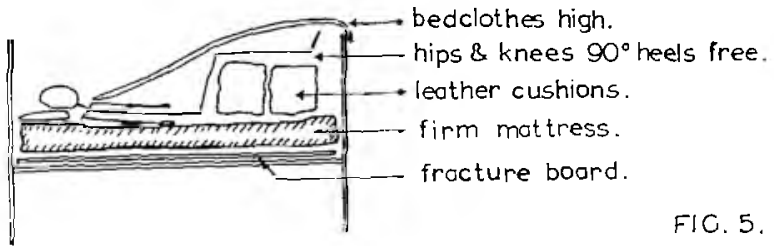

Notice that the first one is slightly wedged, and that the heels are free. (The bed clothes must not press down on the patients feet!). This position allows full relaxation of the abdominals, hip and knee flexors, eliminating the increased tension of the back extensors. Due to better general relaxation the lordosis decreases and the pain almost disappears. It was amazing to see the difference in these patients. This position is used even when pelvic traction is given and during static exercising of all trunk muscles, using the arms and legs.

(b) Spastic hemi- and paraplegics got great relief of pain and spasm after $1-2$ courses of intramuscular A.C.T.H. What it exactly does, no one knows, but it certainly aided relaxation (and thus exercising and walking ability).

(c) Rheumatic cases did not respond so well to watertherapy, although doing completely free exercises in water was enjoyed by everyone. They did however respond remarkably well to ice-therapy!

(d) Great emphasis was laid on the importance of teaching patients back and hip discipline. They were told, each time they came for treatment, how to lift, sit, bend, make up beds, wash, do gardening, etc. impressing on them to use their knees, and to keep their backs straight. For hip-discipline, they were advised to walk with one or two sticks, to sic correctly and to change posture and movement constantly (e.g. to stand, then sit, then walk, etc.).

(e) When teaching a patient to go up and down steps, try, as soon as possible to go to the normal pattern, i.e.:

(i) note that when going up steps, your forefoot is put on the stair-not the whole foot.

(ii) when going down, first the toe and then the heel is put down.

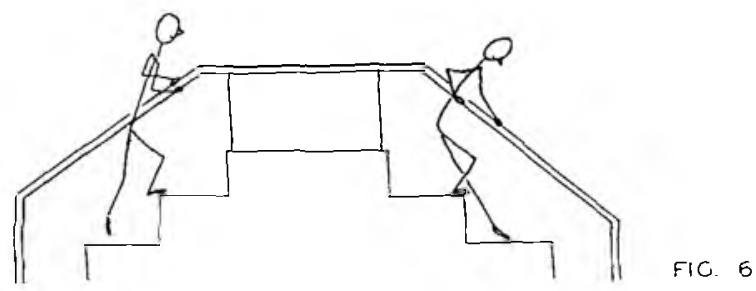

If the patient is afraid, it is often a good idea to let him descend somewhat obliquely, facing the rail. If he should fall he can just grab the rail, and is immediately safe.

( $f$ ) No electro therapy was given to Bell's Palsy cases, as the medical people believe that it does not do them much good, also that it is often uncomfortable or even painful to the patient. Using ice to effect relaxation or stimulation, following with active P.N.F.-type of exercises (stretch reflex, command, overflow, etc.), far better and quicker results were obtained.

These are a few general ideas. In a following article I will discuss muscle re-education and compensatory movements as done in Switzerland. 